\title{
Evaluation the Progesterone and Estrogen Receptor (PR \& ESR) Level and Their Role in Medical Treatment of Patients with Endometriosis
}

\section{Tahereh Poordast}

Shiraz University of Medical Sciences

\section{Saeed Alborzi}

Shiraz University of Medical Sciences

\section{Ziba Kiani}

Shiraz University of Medical Sciences

\section{Elham Askary}

Shiraz University of Medical Sciences

\section{Kefayat Chamanara}

Shiraz University of Medical Sciences

Navid Omidfar ( $\nabla$ omidfar@gmail.com )

Shiraz University of Medical Sciences

\section{Mansoureh Shokripour}

Shiraz University of Medical Sciences

Alimohammad Keshtvarz Hesam Abadi

Shiraz University of Medical Sciences

\section{Research}

Keywords: Endometriosis surgery, Dysmenorrhea, Dyspareunia, Medical treatment

Posted Date: November 1st, 2021

DOI: https://doi.org/10.21203/rs.3.rs-991753/v1

License: (1) (1) This work is licensed under a Creative Commons Attribution 4.0 International License. Read Full License 


\section{Abstract \\ Background}

As the endometriosis is a hormone dependent disease, this study designed to determine a cut-off point for selecting the appropriate treatment based on the hormone receptors of endometriosis lesions.

\section{Methods}

In this retrospective cohort study, all symptomatic endometriotic patients, between March 2017 to March 2019, was divided into two groups: responding and non-responding to hormone therapy following endometriosis surgery. Pathological slides of 72 patients were immunohistologically evaluated for progesterone (PR) and estrogen receptor (ESR) levels.

\section{Results}

Based on the rock curve, the presence of $70 \%$ of estrogen ( $P$ value: 0.001$)$ and $80 \%$ of progesterone receptors ( $P$ value $=0.005)$, as well as $60 \%$ estrogen ( $P$ value: 0.1065$)$ and $40 \%$ of progesterone receptors ( $P$ value: 0.1699 ) in the pathology sample based on $\mathrm{H}$ score can predict the appropriate response to hormonal treatment of dyspareunia and dysmenorrhea respectively. Dysmenorrhea in the presence of endometrioma showed the best response to OCP compared to the progesterone treatment $(69.4 \%$ versus $27.8 \%$ ), while the response of dyspareunia in the presence of the DIE lesions showed the best response to progesterone treatment ( $75 \%$ versus $27.8 \%$ ).

\section{Conclusion}

Response to treatment of dysmenorrhea and dyspareunia is directly related to the increase of $\mathrm{H}$ score. Gynecologist can make the right hormonal treatment based on the specific pattern of IHC staining obtained from patients 'surgical specimens, which leads to improved quality of life and also effective pain reduction after operation as well as recurrent rate.

\section{Background}

Endometriosis is a complex disease that is commonly seen in women of reproductive age and is defined as the presence of endometrial glands and stroma outside the uterine cavity [1]. It is characterized by the presence of dyspareunia, dysmenorrhea and infertility in about $10 \%$ of women of reproductive age [2].

The goal of treatment for this disease is to reduce inflammation and disease activity and thus reducing the pain. For this purpose, several treatments have been suggested, including hormonal and nonhormonal therapies (GNRH, OCP, Progestin, NSAIDs, and etc.) [3]. 
The pathophysiology of endometriosis is not fully understood, but estrogen dependence and progesterone resistance have been shown to cause and maintain the endometriotic lesions [4]. In the endometrial implants, estradiol typically stimulates cell proliferation and progesterone stimulates cell differentiation. The function of ovarian hormones is mediated by estrogen ( $\alpha$ and $\beta$ ) or ( 1 and 2$)$ and progesterone receptors ( $A$ and $B$ ). Previous studies have shown that in endometriosis lesions, overexpression of hormone receptors including high ER2 / ER1 ratio and, also decreased PR expression plays a role. This receptor-mediated signal disorder affects cellular behavior and causes different responses to hormonal therapies [5].

One of the most common hormonal treatments for endometriosis is the use of progesterone or compounds containing it. Progesterone (preg-4-ene-3, 20-dione) is a natural cholesterol catabolite of cyclopentanephydrofentanthrene (cyclopentanoperhydrophenanthrene) that is naturally produced in the corpus luteum [6]. Progesterone works by regulating endometrial decidualization and inhibiting estrogen derived endometrial proliferation $[6,7]$. However, in some patients it has been observed that despite the similarity of serum progesterone levels in healthy and endometriotic women, endometriosis lesions do not respond adequately to the progesterone [8]. It seems Progesterone receptor (PR) expression changes in endometriosis lesions [9-11].

Although available sources strongly support the benefits of long-term use of hormone therapy after surgery to prevent recurrence and disease-related symptoms, especially dysmenorrhea, lack of improvement in some patients may suggest an inappropriate response to the routine hormonal therapies in these cases. This is especially true for those who relapse despite receiving the hormone therapy after surgery $[6,10,12,13]$.

In addition, the production of estradiol (intracrine and paracrine) in endometriotic lesions increases the concentration of steroid hormones and enhances the estrogenic effect. Endometriotic lesions excert a lower level of estradiol inactivation compared to eutopic endometrium, which may further enhance local effect. Few studies have investigated the role of progesterone receptor in patients with endometriosis and its effect on treatment failure and recurrence of disease in some of these patients [6,13-15], however they focused on dysmenorrhea and endometrioma recurrence rather than dyspareunia and DIE lesions [15].

Therefore, the aim of this study was to measure the levels of progesterone (PR) and estrogen receptors (ESR) in endometriosis lesions and determine a cut-off for selecting the appropriate treatment based on the hormone receptors of these lesions to help improve the quality of life of patients with endometriosis better than before.

\section{Methods}

This study was designed as a retrospective cohort study. We enrolled all symptomatic patients aged 20 to 45 years in whom endometriosis was confirmed by physical examination, history taking, and imaging techniques who were referred to two referral governmental hospitals between March 2017 to March 2019. 
The approval of the local ethics committee was obtained (Code: IR.SUMS.REC.1398.1395), and all the patients gave informed consent to the protocol.

The inclusion criteria were as follows: women with a definitive diagnosis of endometriosis based on pathology report, complete demographic and follow-up information even with a phone call, those whose VAS score in any of pain symptoms of endometriosis (dysmenorrhea or dysparonea) was moderate to severe before surgery [16], with data about pain response to progesterone-based therapies after surgical treatment, unwillingness to conceive until at least two years after surgery, tendency to continue treatment, even though they knew they would not have a routine and monthly mensturation period and those who have had regular follow-ups after surgery.

Exclusion criteria were as follows: incomplete demographic and follow-up information, those with diseases such as $\mathrm{GI}$ or urinary tract diseases, as well as those with PID disease, taking hormonal or infertility drugs up to six months before surgery and having previous endometriosis surgery, $\mathrm{FSH}>10$ before operation, or age $>45$ at the time of operation, those who stopped taking the drug after the operation for any reason or used it irregularly and existence of concomitant malignancy and unavailability of pathology slides.

Patients' records were used to collect data. Demographic information including patients' age, BMI, pain symptoms, the stage of endometriosis disease according to ASRM (American society for reproductive medicine) classification, affected area, type of hormone therapy, duration of treatment and response to treatment were recorded in a checklist.

During operation after all adhesions were lysed and excised by sharp dissection to fully mobilize the ovaries and ovarian cystectomy, all areas of superficial active endometriosis involving the other ovary or the pelvic peritoneum were fulgurated. Deep infiltrative endometriosis lesions located in the utero-sacral, retrocervical, rectovaginal area, Douglas pouch, rectum and bladder were separated and resected from the surrounding normal tissue with preserving important structures such as ureter, uterine vessels and pelvic nerves.

Patients were aware of the two methods of treatments before their operation, and they had been informed that none has been proven to be superior yet. All of them were on stage three or four of diseases according to the ASRM classification.

Medical treatment was started on the day of discharge for patients based on the patient's preference, which included $30 \mathrm{mg}$ daily medroxyprogesterone or contraceptive pills with $0.03 \mathrm{mg}$ ethinyl estradiol and 15 ug desogestrel. All patients were followed for at least 12 months after surgery ( 8 to 25 months).

The sample size was determined by NCSS software, $80 \%$ power and the first type error of $5 \%$ and using similar articles (sensitivity $=93 \%$ ).

After patients selection based on inclusion and exclusion criteria and extracting the required data from patients' records, Pathological slides were examined and stained immunohistochemically for PR and 
ESR.

First, the samples in paraffin was cut to a size of 5 micrometers and placed on a slide $[17,18]$. The slides are deparaffined and hydrated by a series of washes with xylene and ethanol. After rinsing in distilled water for 5 minutes, the slides are immersed in $0.01 \mathrm{M}$ sodium citrate buffer for 15 minutes and then cooled for 45 minutes.

Then the slides are rinsed in PBS 1\% (Tween 20) PBST for 5 minutes and cut with a hydrophobic pen. Endogenous peroxidase is quenched for 5 minutes with $3 \%$ hydrogen peroxide and then rinsed with PBST for 5 minutes. Non-specific binding with $5 \%$ natural goat serum in PBST is blocked for 1 hour at room temperature.

The primary used antibodies (PR H-190) (sc_7208; 1: 800) were purchased from Santa Cruz Biotechnology (Santa Cruz, CA). The slides were incubated with the initial antibody at $4{ }^{\circ} \mathrm{C}$ overnight. Normal goat IgG (Biotechnology Santa Cruz) was used as a negative control.

Natural endometrium on day 14 was also considered as a positive control. Goat antirabbit biotinylated secondary antibody was used for PR (Vector Laboratories, Burlingame, CA) and for 1 hour at room temperature.

Slides were washed in 1\% PBS and incubated at ABC Elite (Vector Laboratories) for 30 minutes at room temperature and then washed again in 1\% PBS and incubated with diaminobenzidine (Vector Laboratories) for 41 seconds.

Then exposed to hematoxylin as a counterstain for 30 seconds. Finally, the slides were rinsed with ethanol and xylene for 5 minutes and washed and mounted by Permount (Thermo Fisher Scientific, Waltham, MA) $[6,19,20]$.

$\mathrm{H}$ score for immunohistochemical staining was determined based on the percentage of receptor staining for each slide. Each slide was scored separately by two pathologists unaware of the subject, and $\mathrm{H}$ scores were averaged. The $\mathrm{H}$ score was calculated using the modified $\mathrm{H}$ score, which is expressed as: negative (score 0 ), weak positive (score 1 ), positive (score 2 ) and strongly positive (score 3 ) $[7,19]$.

Finally, the collected data were entered in SPSS software version 20. For the final analysis, patients were divided into two groups based on response to treatment and the data of the two groups were compared. Qualitative data were compared between the two groups using chi-square test and if necessary with Fisher's exact test, and quantitative data were compared using t-test. Kramer-Phi and Spearman tests were used to examine the correlation. $P$ value less than 0.05 was considered statistically significant.

\section{Results}

96 patients who met the inclusion criteria were included in this study and the medical records of these patients were analyzed to evaluate their response to medical treatment. But in only 72 patients, tissue 
Demographic characteristics based on the improvement of dysmenorrhea or dyspareunia were the same for the respondent and non-respondent groups and were not statistically significant (Table 1). Mean age of patients was $34.71 \pm 6.01$ and the mean BMI was $24.04 \pm 4.16$.

Table 1

Demographic characteristics and clinical data of patients with endometriosis

\begin{tabular}{|c|c|c|c|c|c|c|c|}
\hline \multirow[t]{2}{*}{ Variable } & & \multicolumn{2}{|c|}{$\begin{array}{l}\text { Recovery based on } \\
\text { dysmenorrhea( } \mathrm{N})\end{array}$} & \multirow[t]{2}{*}{$\begin{array}{l}P \\
\text { value }\end{array}$} & \multicolumn{2}{|c|}{$\begin{array}{l}\text { Recovery based on } \\
\text { dyspareunia(N) }\end{array}$} & \multirow[t]{2}{*}{$\begin{array}{l}P \\
\text { value }\end{array}$} \\
\hline & & Yes & No & & Yes & No & \\
\hline \multirow{3}{*}{$\begin{array}{l}\text { Economic } \\
\text { situation }\end{array}$} & Poor & 32 & 8 & \multirow[t]{3}{*}{0.472} & 30 & 5 & \multirow[t]{3}{*}{0.694} \\
\hline & Normal & 27 & 7 & & 24 & 3 & \\
\hline & Rich & 6 & 0 & & 4 & 0 & \\
\hline \multirow[t]{2}{*}{ Infertility } & Yes & 8 & 2 & \multirow[t]{2}{*}{1.000} & 7 & 2 & \multirow[t]{2}{*}{0.607} \\
\hline & No & 62 & 14 & & 53 & 8 & \\
\hline \multirow{2}{*}{$\begin{array}{l}\text { Menstrual } \\
\text { cycle }\end{array}$} & Regular & 58 & 11 & \multirow[t]{2}{*}{1.000} & 49 & 5 & \multirow[t]{2}{*}{0.131} \\
\hline & Irregular & 19 & 4 & & 16 & 5 & \\
\hline \multirow{3}{*}{$\begin{array}{l}\text { Type of } \\
\text { treatment }\end{array}$} & GNRH-a & 1 & 0 & \multirow[t]{3}{*}{0.895} & 1 & 0 & \multirow[t]{3}{*}{0.588} \\
\hline & OCP & 41 & 8 & & 29 & 6 & \\
\hline & Progesterone & 38 & 8 & & 37 & 4 & \\
\hline
\end{tabular}

\section{$\mathrm{N}$ : number of patients. GNRH-a: gonadotropine releasing hormone agonist}

Based on ROC chart analysis with two threshold strategy, all patients were classified into 3 groups based on estrogen and progesterone receptor density: High ( $\mathrm{H}$-score $\geq 80$ ), medium ( $\mathrm{H}$-score 6 to 80 ) and low (H-score $\leq 5)$ and also for the estrogen receptor density: High (H-score $\geq 70)$, medium (H-score 6 to 70$)$ and low (H-score $\leq 5)$ (Tables 2).

$\mathrm{H}$-score $\leq 5$ was selected due to high sensitivity $(100 \%)$ and $\mathrm{H}$-score $\geq 80$ for the PR and $\geq 70$ for the ERS was were selected due to high specificity (100\%).

Response to treatment of dysmenorrhea and dyspareunia was directly related to the increase of $\mathrm{H}$ score, which is shown in Table 2. Due to the very small sample size in the group with a low $\mathrm{H}$ score, we cannot trust the results obtained in this group. 
Table 2

Prediction of Response based on dysmenorrhea and dyspareunia using PR and ESR Status

\begin{tabular}{|llllllll|}
\hline & & \multicolumn{3}{c|}{ Recovery based on dysmenorrhea $(\mathrm{N})$} & \multicolumn{3}{l|}{ Recovery based on dyspareunia (N) } \\
\cline { 2 - 9 } & & Yes & No & Response rate\% & Yes & No & Response rate\% \\
\hline PR & High & 36 & 8 & 81.8 & 29 & 2 & 93.5 \\
\cline { 2 - 9 } H-SCORE & Medium & 33 & 5 & 86.8 & 28 & 5 & 84.8 \\
\cline { 2 - 9 } & Low & 3 & 0 & & 3 & 0 & \\
\hline ER & High & 40 & 8 & 83.3 & 36 & 2 & 94.7 \\
H-SCORE & Medium & 32 & 5 & 86.5 & 24 & 5 & 82.8 \\
\cline { 2 - 9 } & Low & 1 & 0 & & 1 & 0 & \\
\hline
\end{tabular}

The ROC curve (Figure 1) for predicting the dysmenorrhea response is based on the H score, which shows the area below the curve 0.677 for ESR ( $95 \% \mathrm{Cl}: 0.559$ to 0.780 ). This predicts the good response of dysmenorrhea to treatment with a sensitivity of 77.27 and a specificity of 55.56 in the presence of $60 \%$ estrogen receptor in the tissue sample ( $P$ value: 0.1065$)$.

And for PR, the area below the curve shows 0.642 (95\% Cl: 0.523 to 0.750$)$. This predicts the response to treatment of dysmenorrhea with a sensitivity of 95.45 and a specificity of 33.33 in the presence of $40 \%$ of progesterone receptors in the tissue sample ( $P$ value: 0.1699$)$.

The ROC curve for predicting the dyspareunia response is based on the $\mathrm{H}$ score for the ESR, which shows the area below the curve 0.743 (\%95 Cl: 0.620 to 0.842 ).

This predicts the response of dyspareunia to treatment with a sensitivity of 60.66 and a specificity of 100 in the presence of $70 \%$ estrogen receptor in the tissue sample (P value: 0.001$)$.

And for PR shows the area under curve 0.742 (95\% Cl: 0.619 to 0.842$)$.

This predicts the response of dyspareunia to treatment with a sensitivity of 41.67 and a specificity of 100 in the presence of $80 \%$ of progesterone receptors in the tissue sample ( $P$ value $=0.005)$.

According to Table 3, the improvement of dysmenorrhea and dyspareunia in tubular lesions did not depend on the type of treatment, and all tubular lesions responded to OCP and progesterone similarly. 
Table 3

Endometriosis pain relief based on the location and type of treatment

\begin{tabular}{|llll|}
\hline \multirow{3}{*}{ Recovery of dysmenorrhea } & & OCP & Progesterone \\
& OMA & $69.4 \%$ & $27.8 \%$ \\
\cline { 2 - 4 } & DIE & $28.6 \%$ & $71.4 \%$ \\
\cline { 2 - 4 } & Tube & $50 \%$ & $50 \%$ \\
\hline Recovery of dyspareunia & OMA & $55.4 \%$ & $41.2 \%$ \\
\cline { 2 - 4 } & DIE & $25 \%$ & $75 \%$ \\
\hline & Tube & $50 \%$ & $50 \%$ \\
\hline
\end{tabular}

In the case of endometrioma, dysmenorrhea respond better to the OCP, but about dyspareunia significant difference between OCP and progesterone in relieving pain does not exist.

In the case of DIE lesions, the response of dysmenorrhea and dyspareunia to progesterone treatment was, obviously better than OCP.

According to Table 4, In the case of OMA, DIE and tubal lesions dysmenorrhea will respond better to treatment if estrogen and progesterone receptor levels are higher than cutoff point.

The percentage of patient with estrogen receptor over than cut off point in OMA and Tubal lesion is higher than DIE lesions, and the percentage of patient with progesterone receptor over than cut off point in DIE is higher than OMA and Tubal lesions, although this difference is not statistically significant.

Table 4

Percentage of patients recovering from pain based on lesion location and hormone receptor

\begin{tabular}{|c|c|c|c|c|c|c|c|c|}
\hline \multirow[b]{2}{*}{ Receptor } & \multicolumn{4}{|c|}{ Improvement of dysmenorrhea } & \multicolumn{4}{|c|}{ Improvement of dyspareunia } \\
\hline & ESR & & PR & & ESR & & PR & \\
\hline Receptor cut of & $>60$ & $<60$ & $>40$ & $<40$ & $>70$ & $<70$ & $>80$ & $<80$ \\
\hline \multicolumn{9}{|c|}{ Percentage of patients in each group } \\
\hline OMA & 75.6 & 24.4 & 90.2 & 9.8 & 70.7 & 29.3 & 43.9 & 56.1 \\
\hline DIE & 67.7 & 32.3 & 86.7 & 13.3 & 61.3 & 38.7 & 60 & 40 \\
\hline Tube & 78.6 & 21.4 & 78.6 & 21.4 & 78.6 & 21.4 & 57.1 & 42.9 \\
\hline
\end{tabular}

\section{Discussion}


In this study, we showed that the levels of progesterone and estrogen receptors in endometriosis lesions could strongly predict the response of these patients to drug therapy (including OCP and progesterone). Our results showed that the response to treatment of dysmenorrhea and dyspareunia is directly related to the increase of $\mathrm{H}$ score, which is shown in Table 2.

Based on previous studies in this field as well as studies on breast lesions, we decided to perform an innovation and set a threshold for the amount of estrogen and progesterone receptors in endometriosis lesions. Therefore, we set a cut-off point to predict the response to treatment of these lesions with the following goals: to improve the quality of life in these patients and define the reduction of the financial burden of this disease on society due to the long-term need for treatment and follow-up in these patients. So for predicting the appropriate response of dyspareunia to treatment based on the Roc curve ( $P$ value $<0.05$ ) we set a $70 \%$ threshold for tissue estrogen and a $80 \%$ for progesterone receptors and $60 \%$ threshold for tissue estrogen and a $40 \%$ for progesterone receptors ( $P$ value $>0.05$ ) to predict the appropriate response of dysmenorrhea to treatment .

Few studies have examined the status of PR and ESR and its role in predicting response to treatment in patients with endometriosis $[12,21,22]$. Similar to us, in a study conducted by Flores et al in 2018 , they examined the status of the progesterone receptor and its role in predicting the response of endometriosis lesions to progesterone treatment. Histopathologic $(\mathrm{H})$ score was used to determine the qualitative status of PR. H score was higher in respondents than non-respondents patients. Treatment response status was strongly associated with progesterone receptor status. They concluded depending on the number of receptors in endometriosis, different hormone-based therapies can be used after surgery. So determining the amount of progesterone receptor may be very helpful in determining a new goal-based approach to the treatment of endometriosis lesions [12].

In 2017, Hou et al. examined the role of predictive biomarkers in the accurate treatment of endometriosis. They investigated the effect of bazedoxifene (BZA) and medroxy progesterone acetate (MPA) on the expression of progesterone receptor (PR), estrogen receptor (ER) and aromatase enzyme (CYP19A1) genes in cell culture media obtained from patient biopsy with endometriosis. They concluded that the degree of PR expression may predict progesterone resistance as well as response to treatment of endometriosis lesions [23].

It remains to be seen whether the heterogeneity observed in the expression of hormone receptors in different types of tissues can explain the difference in patients' response to hormone therapy?

In our study, in the case of OMA, DIE and tubal lesions dysmenorrhea and specially dyspareunia will respond better to treatment if estrogen and progesterone receptor levels are higher than cutoff point. As we showed in Table 4 the percentage of patient with estrogen receptor over than cut off point in OMA and Tubal lesions is higher than DIE, and the percentage of patient with progesterone receptor over than cut off point in DIE is higher than OMA and Tubal lesions, although this difference is not statistically significant. Due to the higher number of progesterone receptors in the tubal and DIE lesions compared to OMA, the better response of dyspareunia in these lesions to progesterone treatment can be justified. Our 
data also confirm previous findings that showed variable levels of progesterone receptors in various endometriosis lesions, so it is best to treat all endometriosis lesions based on the expression of their hormone receptors [24].

Similar to us Colón-Caraballo et al in 2018 conducted a study aimed at expressing the concentrations of the steroid receptor hormones in different types of endometriotic lesions and also eutopic endometrium. This comparison was performed between endometriosis and normal women (control group) using tissue microarray method (TMA). They showed that ovarian lesions showed the lowest expression of ESR1 (alpha estrogen) and PGR (progesterone) and the highest expression of ESR2 (beta estrogen), while the fallopian tube lesions had the highest expression of all 3 receptors. The highest ESR2: ESR1 ratio was observed in ovarian and endometrial secretory lesions [25]. Other studies in this area also show overexpression of ESR2 / ERS1 in endometriosis tissues, which lead to increase proliferation in lesions and also induced progesterone resistance $[13,26,27]$. There is a clear association between ESR, and PR expression and its secretion cycle with the development and progression of endometriosis. Increased expression of $B$ estrogen receptor leads to more local production of estrogen as well as suppression of progesterone receptors in endometriosis tissue. In addition, there is a lack of progesterone receptors in these tissues, which leads to progesterone resistance, which is commonly reported as estrogendependent and progesterone-resistant in the endometriosis tissue [28]. Thus, the IHC expression characteristics of nuclear isoforms of ESR and PR in target tissue sampled during surgery can predict the response to commonly prescribed drugs.

Given that the overexpression of ESR2 / ESR1 in hormone-dependent malignancies such as breast and prostate cancer, and also endometrial cancers, is associated with the high grade tumoral process and predicts clinical outcome including overall survival rate of patients, we can use the results of this study for the same purposes in patients with endometriosis $[19,29]$.

According to Table 3, the improvement of dysmenorrhea and dyspareunia in tubular lesions did not depend on the type of treatment, and all tubular lesions responded to OCP and progesterone similarly. Here Sampson's hypothesis is strengthened that removing the tubes and clearing the pelvis of endometriosis lesions eliminates the pathophysiology of the disease [2]. But in the case of endometrioma, dysmenorrhea may respond better to treatment with the $\mathrm{OCP}$, however in dyspareunia doesn't exist significant difference between OCP and progesterone in relieving pain .In the case of DIE lesions, the response of dysmenorrhea and dyspareunia to progesterone treatment was better than OCP.

So, we found that there was a difference in progesterone receptor levels between patients and even in an individual, based on the type of endometriotic lesions. This issue can predict the response of treatment in endometriotic patients and help to choose a better treatment for each patient and may prevent recurrence of the disease after surgery.

Significant improvement of dyspareunia compared to dysmenorrhea in our study supports the results that extra pelvic endometriosis lesions have higher levels of PR than ovarian endometrioma lesions [30]. 
The results show that a gynecologist can make the right hormonal treatment (such as OCP and Progesterone) based on the specific pattern of IHC staining obtained from patients 'surgical specimens, which leads to improved quality of life and also effective pain reduction after operation in these patients. Thus, recurrence of the disease in the reproductive ages can be prevented by prescribing appropriate treatment.

The limitation of our study is the lack of estrogen subtype determination, because by comparing the difference in ESR2 / 1 ratio in endometrioma and other DIEs lesions.

\section{Abbreviations}

PR

Progesterone

ESR

Estrogen receptors

ASRM

American society for reproductive medicine

GNRH-a

Gonadotropine releasing hormone agonist

BZA

Bazedoxifene

MPA

Medroxy progesterone acetate

TMA

Tissue microarray method

\section{Declarations}

\section{Acknowledgements}

The authors would like to thank all the staff members of our surgical and laboratory units for their expert assistance in data collection.

\section{Authors' contributions}

TP: Conception, design of study and data revising; SA: design of study \& final approach; ZK: Patient recruitment \& data collection; EA: Data interpretation \& manuscript preparation; KC: Patient recruitment, drafting \& design; NO: Conception, design of study and data revising; MS: Patient recruitment, drafting \& design; AKHA: Data analysis and interpretation; All authors read and approved the final manuscript.

\section{Funding}


This research did not receive any specific grant from funding agencies in the public, commercial, or notfor-profit sectors.

\section{Availability of data and materials}

The datasets used and/or analysed during the current study are available from the corresponding author on reasonable request.

Ethics approval and consent to participate: The approval of the local ethics committee was obtained (Code: IR.SUMS.REC.1398.1395), and all the patients gave informed consent to the protocol. All procedures followed were in accordance with the ethical standards of the responsible committee on human experimentation (institutional and national) and with the Helsinki Declaration of 1964 and its later amendments.

Consent for publication: Not applicable.

Competing interests: The authors declare that they have no competing interests.

\section{References}

1. Olive DL, Schwartz LB. Endometriosis. N Engl J Med. 1993;328(24):1759-69. https://doi.org/10.1056/nejm199306173282407.

2. Burney RO, Giudice LC. Pathogenesis and pathophysiology of endometriosis. Fertil Steril. 2012;98(3):511-9. https://doi.org/10.1016/j.fertnstert.2012.06.029.

3. Giudice LC. Clinical practice. Endometriosis. N Engl J Med. 2010;362(25):2389-98. https://doi.org/10.1056/NEJMcp1000274.

4. Greene AD, Lang SA, Kendziorski JA, Sroga-Rios JM, Herzog TJ, Burns KA. Endometriosis: where are we and where are we going? Reproduction. 2016;152(3):R63-78. https://doi.org/10.1530/rep-160052.

5. Bergqvist A, Fernö M. Estrogen and progesterone receptors in endometriotic tissue and endometrium: comparison according to localization and recurrence. Fertil Steril. 1993;60(1):63-8.

6. Wingfield M, Macpherson A, Healy DL, Rogers PA. Cell proliferation is increased in the endometrium of women with endometriosis. Fertil Steril. 1995;64(2):340-6. https://doi.org/10.1016/s00150282(16)57733-4.

7. Patel BG, Rudnicki M, Yu J, Shu Y, Taylor RN. Progesterone resistance in endometriosis: origins, consequences and interventions. Acta Obstet Gynecol Scand. 2017;96(6):623-32. https://doi.org/10.1111/aogs.13156.

8. Ramathal CY, Bagchi IC, Taylor RN, Bagchi MK. Endometrial decidualization: of mice and men. Semin Reprod Med. 2010;28(1):17-26. https://doi.org/10.1055/s-0029-1242989. 
9. Bulun SE, Cheng YH, Yin P, Imir G, Utsunomiya H, Attar E, et al. Progesterone resistance in endometriosis: link to failure to metabolize estradiol. Mol Cell Endocrinol. 2006;248(1-2):94-103. https://doi.org/10.1016/j.mce.2005.11.041.

10. Attia GR, Zeitoun K, Edwards D, Johns A, Carr BR, Bulun SE. Progesterone receptor isoform A but not $B$ is expressed in endometriosis. J Clin Endocrinol Metab. 2000;85(8):2897-902. https://doi.org/10.1210/jcem.85.8.6739.

11. Cakmak H, Taylor HS. Molecular mechanisms of treatment resistance in endometriosis: the role of progesterone-hox gene interactions. Semin Reprod Med. 2010;28(1):69-74. https://doi.org/10.1055/s-0029-1242996.

12. Flores VA, Vanhie A, Dang T, Taylor HS. Progesterone Receptor Status Predicts Response to Progestin Therapy in Endometriosis. J Clin Endocrinol Metab. 2018;103(12):4561-8. https://doi.org/10.1210/jc.2018-01227.

13. Bulun SE, Cheng YH, Pavone ME, Xue Q, Attar E, Trukhacheva E, et al. Estrogen receptor-beta, estrogen receptor-alpha, and progesterone resistance in endometriosis. Semin Reprod Med. 2010;28(1):36-43. https://doi.org/10.1055/s-0029-1242991.

14. van Diest PJ, van Dam P, Henzen-Logmans SC, Berns E, van der Burg ME, Green J, et al. A scoring system for immunohistochemical staining: consensus report of the task force for basic research of the EORTC-GCCG. European Organization for Research and Treatment of Cancer-Gynaecological Cancer Cooperative Group. J Clin Pathol. 1997;50(10):801-4. https://doi.org/10.1136/jcp.50.10.801.

15. Somigliana E, Vercellini P, Vigano P, Benaglia L, Busnelli A, Fedele L. Postoperative medical therapy after surgical treatment of endometriosis: from adjuvant therapy to tertiary prevention. J Minim Invasive Gynecol. 2014;21(3):328-34. https://doi.org/10.1016/j.jmig.2013.10.007.

16. Seracchioli R, Mabrouk M, Frascà C, Manuzzi L, Savelli L, Venturoli S. Long-term oral contraceptive pills and postoperative pain management after laparoscopic excision of ovarian endometrioma: a randomized controlled trial. Fertil Steril. 2010;94(2):464-71. https://doi.org/10.1016/j.fertnstert.2009.03.083.

17. Rackow BW, Taylor HS. Submucosal uterine leiomyomas have a global effect on molecular determinants of endometrial receptivity. Fertil Steril. 2010;93(6):2027-34. https://doi.org/10.1016/j.fertnstert.2008.03.029.

18. Lee B, Du H, Taylor HS. Experimental murine endometriosis induces DNA methylation and altered gene expression in eutopic endometrium. Biol Reprod. 2009;80(1):79-85. https://doi.org/10.1095/biolreprod.108.070391.

19. Miró AM, Sastre-Serra J, Pons DG, Valle A, Roca P, Oliver J. 17 $\beta$-Estradiol regulates oxidative stress in prostate cancer cell lines according to ERalpha/ERbeta ratio. J Steroid Biochem Mol Biol. 2011;123(3-5):133-9. https://doi.org/10.1016/j.jsbmb.2010.12.004.

20. Vassilopoulou L, Matalliotakis M, Zervou MI, Matalliotaki C, Spandidos DA, Matalliotakis I, et al. Endometriosis and in vitro fertilisation. Exp Ther Med. 2018;16(2):1043-51. https://doi.org/10.3892/etm.2018.6307. 
21. Prentice A, Randall BJ, Weddell A, McGill A, Henry L, Horne $\mathrm{CH}$, et al. Ovarian steroid receptor expression in endometriosis and in two potential parent epithelia: endometrium and peritoneal mesothelium. Hum Reprod. 1992;7(9):1318-25. https://doi.org/10.1093/oxfordjournals.humrep.a137848.

22. Bruner-Tran KL, Herington JL, Duleba AJ, Taylor HS, Osteen KG. Medical management of endometriosis: emerging evidence linking inflammation to disease pathophysiology. Minerva Ginecol. 2013;65(2):199-213.

23. Hou Z, Mamillapalli R, Taylor HS. Predictive Biomarkers May allow Precision Therapy of Endometriosis. J Endometr Pelvic Pain Disord. 2017;9(4):279-85. https://doi.org/10.5301/jeppd.5000311.

24. Burney RO, Talbi S, Hamilton AE, Vo KC, Nyegaard M, Nezhat CR, et al. Gene expression analysis of endometrium reveals progesterone resistance and candidate susceptibility genes in women with endometriosis. Endocrinology. 2007;148(8):3814-26. https://doi.org/10.1210/en.2006-1692.

25. Colón-Caraballo M, García M, Mendoza A, Flores I. Human Endometriosis Tissue Microarray Reveals Site-specific Expression of Estrogen Receptors, Progesterone Receptor, and Ki67. Appl Immunohistochem Mol Morphol. 2019;27(7):491-500. https://doi.org/10.1097/pai.0000000000000663.

26. Brandenberger AW, Lebovic DI, Tee MK, Ryan IP, Tseng JF, Jaffe RB, et al. Oestrogen receptor (ER)alpha and ER-beta isoforms in normal endometrial and endometriosis-derived stromal cells. Mol Hum Reprod. 1999;5(7):651-5. https://doi.org/10.1093/molehr/5.7.651.

27. Zannoni GF, Monterossi G, De Stefano I, Gargini A, Salerno MG, Farulla I, et al. The expression ratios of estrogen receptor a (ERa) to estrogen receptor $\beta 1$ (ERß1) and ERa to ERß2 identify poor clinical outcome in endometrioid endometrial cancer. Hum Pathol. 2013;44(6):1047-54. https://doi.org/10.1016/j.humpath.2012.09.007.

28. Shao $\mathrm{R}$, Cao $\mathrm{S}$, Wang $\mathrm{X}$, Feng $\mathrm{Y}$, Billig $\mathrm{H}$. The elusive and controversial roles of estrogen and progesterone receptors in human endometriosis. Am J Transl Res. 2014;6(2):104-13.

29. Chantalat E, Valera MC, Vaysse C, Noirrit E, Rusidze M, Weyl A, et al. Estrogen Receptors and Endometriosis. Int J Mol Sci. 2020;21(8). https://doi.org/10.3390/ijms21082815.

30. Reis FM, Coutinho LM, Vannuccini S, Batteux F, Chapron C, Petraglia F. Progesterone receptor ligands for the treatment of endometriosis: the mechanisms behind therapeutic success and failure. Hum Reprod Update. 2020;26(4):565-85. https://doi.org/10.1093/humupd/dmaa009.

\section{Figures}


ERs

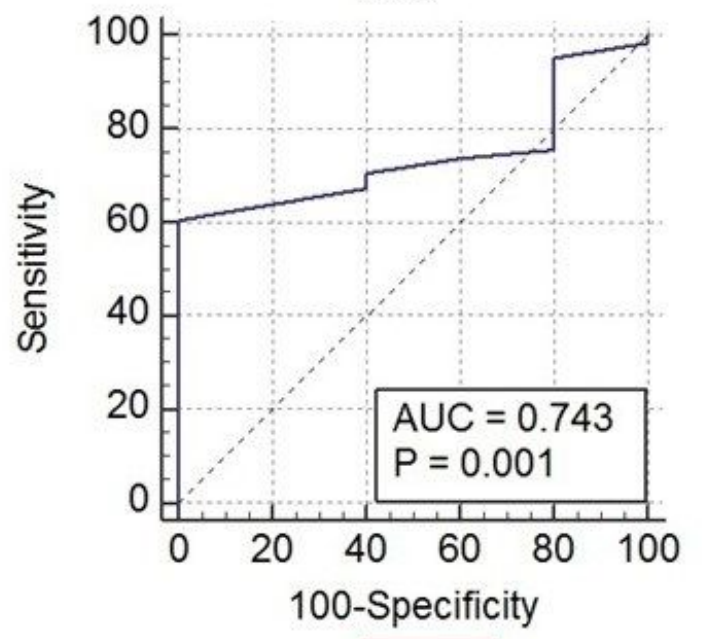

A

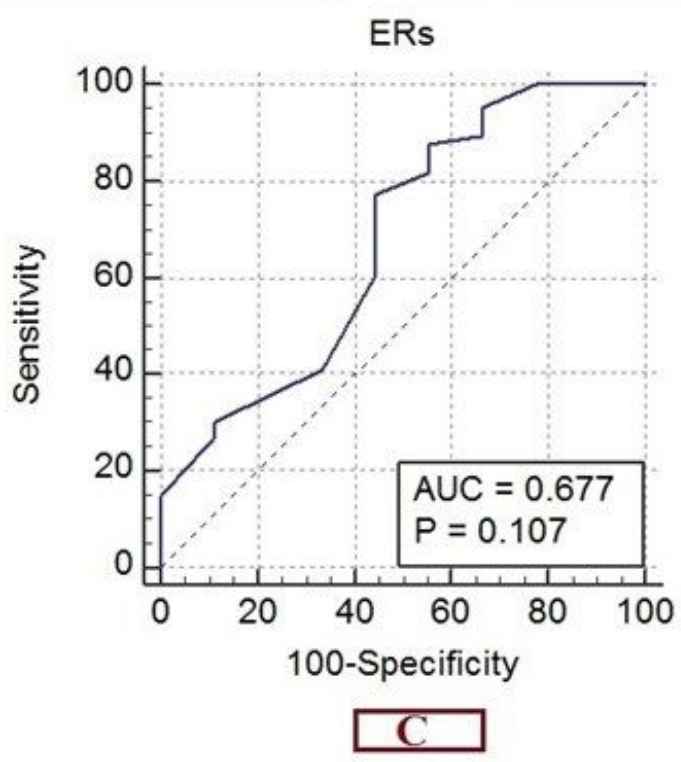

PRs

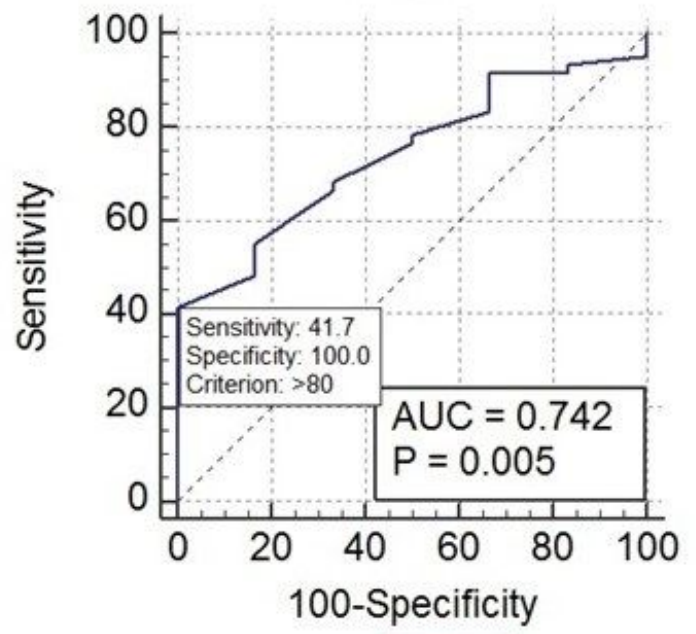

B

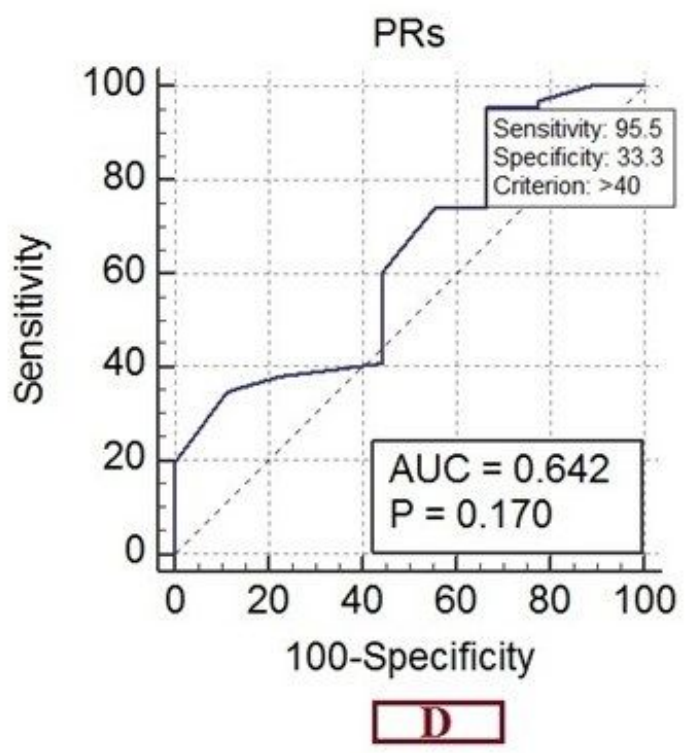

Figure 1

ROC curve for predicting the dysmenorrhea $(A, B)$ and dyspareunia $(C, D)$ response to treatment based on $\mathrm{H}$ score of PR and ESR. 